\section{Teaching Crystallography}

MS23.01.01 TEACHING CRYSTALLOGRAPHY FOR PHYSICS STUDENT IN EGYPT. Karimat El-Sayed, Physics Department, Ain Shans University, Cairo, Egypt

The contents of the crystallography courses given for the undergraduate and post graduate physics students in Egypt are going to be discussed in theis talk. The design of the contents of the undergraduate course were based on the needs of other solid state physics courses: the students for example has to understand: I) the reason for anisotropy in the physical propeties of some materials, 2) the reason for the great difference in the physical and mechanical properties between diamond and graphite, although they have the same chemical composition, 3) the mechanisns which produce intrinsic and extrinsic physical properties and the difference between them, 4) the mode of defects formation such as the point defects, dislocation and stacking faults, 5) to know the difference between, crystalline, poly crystalline and amorphous materials. All these items listed above can only be explained in term of structure.

The contents of the post graduate course (Master degree) are an extension of the undergraduate course and the contents were also designed in order to serve the need of the students. The powder and electron diffraction techniques are adopted in this course for the purpose of characterizing and extracting the microstructural parameters from materials having either intrinsic or extrinsic properties. Those techniques are also applied for: lattice and super lattice detection, phase identification and degree of disordering in disordered materials.

MS23.01.02 CRYSTALLOGRAPHIC SCHOOLSINTHAMAND AND NEIGHBOURING COUNTRIES. Phathana Phavanantha, Chulalongkom University, Bangkok 10330, Thailand

Thai and regional crystallographic schools established as regular university organisations, or as held in conjunction with other major crystallographic events will be discussed with respect to their benefits, diffulties encountered, possible solutions, and suggestions.

Regional crystallographic schools within national universities are organized with prime objectives of pursuing academic excellence, producing competitive graduates, and answering the region's needs in R\&D and training for industry and general public.

Crystallographic interest and teaching in the region coincide with central research themes of each institute based generally on natural products, small molecules, minerals, and industrial or pharmacentical compounds.

Small crops of Thai crystallographers have been trained locally and/ or abroad typically at Chulalongkom University in Bangkok and in the U.K. since three decades ago. Support teceived by crystallographic schools is strongly reflected by the number of graduates wishing to enter the field, and fluctuates somewhat with ongoing situations.

Investment on standard equipments which is out of tune with manpower production and community need invariably hampers development, and correcting attempts appear to be successful. As Thai scientific community is bent on preparation for 1st-generation synchrotron radiation source to be donated from Japan, local schools and crystallographers must arise to this challenge.

Collaboration between crystallographic centres in- and outside the region e.g. Bangkok, Kualalampur, Perth, Songkla and Uppsala has brought much sustainable progress which is to be admired, and their cooperation observed.

Crystallographic Schools on Gems and Computing supported by IUCr, AsCA, CrSJ and TCrA were held as satellites of AsCA' 95 meeting of Asian crystallographers at Chulalongkom University. The schools were fully attended and proven very benefitial to regional participants to leam directly from many intemational experts during this short period. Firm and early commitments by all main organizers based on verifiable block agreement with mutual understanding is much recommended for such regional schools now being expected triannually.
MS23.01.03 TEACHUNG IN RUSSIA; TRADITIONS AND INNOVATIONS. Aslanov L.A. Moscow State University, Department of Chemistry, 119899 Moscow, Russia

Crystallography is being taught in many Universities of Russia as a selfconsistent course of lectures, seminars and practicals or mostly as a tool for the understanding and description of chemical, physical, biological processes and properties of substances. Traditionally the courses of crystallography include the symmetry theory and x-ray crystallography or crystal grow as an application for the material science, chemistry, and mineralogy. There are three stages of the crystallography teaching in Russian Universities: (i) the general course for all students;(ii) specialisation for students who study crystallography for research; (iii) training of students in the research institutes of Academy of Sciences. Two innovations appeared during 5 last years. First, a number of undergraduate students go to the Universities of Europe and USA for a few months up to one year before the final exams in Russian University. Second, the international schools had been arraigned in Moscow and St-Petersburg for Russian and FSU students. The schedule and traditions of crystallography teaching were polished for dozens of years, however the most promising tradition is the innovations in the contents of the crystallographic courses which depend on the specific profile of the University (charge, spin, momentum density; quasicrystals; comprehensive instrumentation; methods of structure determination; powder crystallography etc.). New trend appeared as a financial support for students in the form of different sorts of stipends for the best students apart from the ordinary stipend for nearly all students, i.g. stipend of Russian Presidents Soros (American finansist); some Institutes of Academy of Sciences established stipends for students to attract young generation to the scientific research. As a result of all efforts the number of people who wanted to enter the Russian Universities in 1994 doubled in comparison with 1993 and increased again in 1995.

MS23.01.04 INSTRUCTIONAL MATERIALS. Margaret E. Kastner, Department of Chemistry, Bucknell University, Lewisburg, PA 17837.

Computer aided instruction can be used either by students in independent study or as guided work by the instructor in lectures or computer laboratories. Crystallographic CourseWare is a series of HyperCard stacks describing crystal growth techniques, interpretation of precession photographs, descriptions of symmetry elements, identifying the symmetry, unit cell and asymmetric unit in plane groups, and interpreting the diagrams in the International Tables for Crystallography, Vol. A. Animations are used to sequentially focus attention on particular features. Numerous examples provide the student with practice.

The exercises in plane group symmetry present a pattern and with a few clicks of the mouse the student can place the symbols for the symmetry elements in appropriate positions on the pattern, outline the unit cell, and outline the asymmetric unit. Answers are immediately available, some with animations or further details.

The exercises for reading Volume A present either the crystal coordinates, the symmetry projection diagram or the general position diagram and a template on which the student places symbols of the symmetry elements or general positions. Several exercises have answers immediately available, other answers can be found in the Teaching Edition of Volume $\mathrm{A}$ and a few are only found in Volume $\mathrm{A}$.

Short videotapes can be used to provide an overview of the process by which single crystals yield structural information or provide detailed instruction on how to take precession photographs.

Availability and formats for the current programs and plans for updating or expanding them will be shared. 